Florida International University FIU Digital Commons

All Faculty

$10-10-2014$

\title{
A network analysis of relationship dynamics in sexual dyads as correlates of HIV risk misperceptions among high-risk MSM
}

Kayo Fujimoto

The University of TexasHealth Science Center atHouston

Mark L. Williams

Department of Health Policyand Management, College of Public Health \& Sciences,Florida International University, mlwillia@fiu.edu

Michael W. Ross

The University of TexasHealth Science Center atHouston

Follow this and additional works at: https://digitalcommons.fiu.edu/all_faculty

\section{Recommended Citation}

Fujimoto, Kayo; Williams, Mark L.; and Ross, Michael W., "A network analysis of relationship dynamics in sexual dyads as correlates of HIV risk misperceptions among high-risk MSM" (2014). All Faculty. 78.

https://digitalcommons.fiu.edu/all_faculty/78

This work is brought to you for free and open access by FIU Digital Commons. It has been accepted for inclusion in All Faculty by an authorized administrator of FIU Digital Commons. For more information, please contact dcc@fiu.edu. 


\section{(6) OPEN ACCESS}

\begin{abstract}
- Additional material is published online only. To view please visit the journal online (http://dx.doi.org/10.1136/ sextrans-2014-051742).

${ }^{1}$ Department of Health Promotion \& Behavioral Sciences, School of Public Health, The University of Texas Health Science Center at Houston, Houston, Texas, USA ${ }^{2}$ Department of Health Policy and Management, College of Public Health \& Sciences, Florida International University, Miami, Florida, USA
\end{abstract}

\section{Correspondence to} Dr Kayo Fujimoto, Department of Health Promotion \& Behavioral Sciences, School of Public Health, The University of Texas Health Science Center at Houston, 7000 Fannin Street, UCT 2514, Houston TX 77030-5401, USA; Kayo.Fujimoto@uth.tmc.edu

Received 21 June 2014 Revised 6 September 2014 Accepted 14 September 2014 Published Online First 10 October 2014

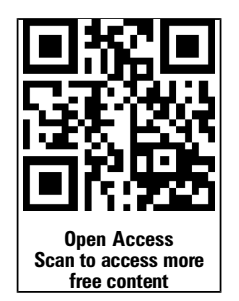

CrossMark

To cite: Fujimoto $\mathrm{K}$, Williams ML, Ross MW. Sex Transm Infect 2015;91: 130-134.

\title{
A network analysis of relationship dynamics in sexual dyads as correlates of HIV risk misperceptions among high-risk MSM
}

\author{
Kayo Fujimoto, ${ }^{1}$ Mark L Williams, ${ }^{2}$ Michael W Ross ${ }^{1}$
}

\section{ABSTRACT \\ Objectives Relationship dynamics influence the} perception of HIV risk in sexual dyads. The objective of this study was to examine the effect of relational dynamics on knowledge or perception of a partner's HIV status in a sample of most at-risk men who have sex with men (MSM): drug-using male sex workers. The study identified relationship dimensions and examined their association with misperceptions about a particular partner's HIV status.

Methods The analytical sample for the study consisted of 168 sexual partnerships of 116 male sex workers and their associates. Exploratory factor analysis was conducted to identify dimensions of the interpersonal relationships in sexual partnerships that were then regressed on 'risky misperceptions' (misperceiving HIV negative when partner's self-report was positive or unknown).

Results Six relationship dimensions of intimate, commitment, socialising, financial, trust and honesty were extracted. Commitment was found to be protective against misperception (adjusted $O R(A O R)=0.45$ ), while trust was not $(A O R=2.78)$. Other factors also were found to be associated with misperception. HIV-negative MSM $(A O R=7.69)$ and partners who were both self-identified as gay ( $A O R=3.57$ ) were associated with misperception, while encounters identified as sex work $(A O R=0.29)$, in which both partners were Caucasian $(A O R=0.16)$, and involved with an older partner $(\mathrm{AOR}=0.90)$ were protective.

Conclusions Couple-based HIV intervention efforts among MSM should consider that less trust and more commitment are protective factors in sexual partnerships.

Men who have sex with men (MSM) are at disproportionately high risk of HIV infection. ${ }^{1}$ Male sex workers, a subgroup of MSM, are at especially elevated risk due to their sexual behaviours, drug use and number of sex partners. ${ }^{2-4}$ Moreover, male sex workers may provide a bridge for HIV transmission between several at-risk groups and the general population, ${ }^{35}$ which suggests that they may be key nodes in HIV transmission networks. A social network perspective defines 'risk-potential network' for disease transmission as a pattern of risk-potential linkages between two people who involve an infectious agent, and in the case of HIV, the risk-potential linkage is sex or injection drug use. ${ }^{6}$ HIV transmission is affected by a social network of confidants, such as close friends, who provide the social and normative contexts in which risky behaviour is facilitated or inhibited. ${ }^{7}$ These contexts are expected to influence the perception of the risk of HIV infection within a sexual network. For example, MSM often presume the HIV status of a sex partner and rely on personal impressions and beliefs to evaluate the riskiness of a sexual encounter with the partner. ${ }^{8}$ While male sex workers tend to endorse social norms about unsafe sex ${ }^{2}$ the social conditions under which the risk perceptions of their sexual encounters are affected may differ significantly from those of other MSM and have rarely been investigated.

The perception that a partner presents risk may greatly affect whether an individual engages in a preventive behaviour in a sexual situation. ${ }^{9}$ In turn, interpersonal dynamics within a sexual partnership may influence perception. Familiarity and trust are two such dynamics. ${ }^{10}$ In general, individuals perceive a sex partner as less likely to be HIV infected if the individual has greater trust in the partner, ${ }^{11}$ perhaps because trust precludes a belief that a sex partner might present risk. ${ }^{12}$ At least one study found that having a high level of trust in a primary partner hinders regular HIV testing. ${ }^{13}$ In sex work encounters, a lack of trust in a sexual relationship has been shown to impede communication about risk between partners. ${ }^{3}$ Among MSM, interpersonal relationships that involve emotional and/or substantive support, such as money, also have been found to be associated with the disclosure of HIV status to the social network members. ${ }^{14}$ Other relational dimensions, such as emotional significance, honesty, intimacy, caring, importance and connectedness, also have been found to be associated with disclosure among MSM. ${ }^{15}$

Interpersonal relations within a sexual partnership may sway the perception of the risk of a sexual encounter. The objective of this study was to examine the relational dynamics that influence the perception of HIV risk associated with a sex partner. The main aims of this study were to: (1) explore the relational dimensions of sexual partnerships and (2) examine their associations with risky misperceptions of a partner's HIV status. This study examined the perceptions of a sex partner's HIV status ${ }^{811} 1617$ and used it as the dependent variables. 'Misperception' was defined as 'incorrect knowledge of a sex partner's diagnosed infection'. Independent variables were the relational dynamics of the sexual partnership. To conduct the analysis, the study expanded the concept of the riskpotential network by identifying relational characteristics ${ }^{16}$ as risk-potential network linkages.

\section{METHODS}

\section{Study design}

Data were collected between May 2003 and February 2004 as part of a larger study of the social, drug use and sexual networks of drug-using 
male sex workers in Houston, Texas. The sample was recruited using a combination of targeted sampling and participant refer$\mathrm{ral}^{4}{ }^{41819}$ as explained in-depth elsewhere. ${ }^{20} 21$ Briefly, focal participants were first recruited and interviewed. Focal participants were eligible to participate if there was a male sex worker 17 years old or older who self-identified as male, had exchanged sex for money with a man in the last 7 days and had smoked crack cocaine or injected an illicit substance in the $48 \mathrm{~h}$ before being screened for the study. Focal participants were then asked to recruit individuals with whom they had used drugs and/or had sex, preferably, or whom they knew socially. In turn, secondary contacts were asked to recruit tertiary contacts. Secondary and tertiary participants were eligible to participate if they were 17 years old and linked to the focal or secondary (referring) participant. To increase the rate of successful referrals, participants were given US\$20 incentive for recruiting a contact who was then interviewed. Interviewed participants were paid US\$30 for their time and to defray the cost of transportation. The study was approved by the Committee for the Protection of Human Subjects at the University of Texas Health Science Center at Houston (IRB\# HSC-SPH-02-009).

\section{Measures}

Respondent's HIV status. Respondent's HIV status was measured by self-report and coded as positive, negative and unknown (including indeterminate).

Sex partner's HIV status. Knowledge of a sex partner's HIV status was determined by the following question, 'Do you think your partner is HIV positive?' (yes or no). The response was linked to that partner's self-reported HIV status.

Outcome variable: Respondent's misperception of his sex partner's HIV status. A two-by-three contingency table of a respondent's perception of the partner's HIV status (indexed in a row) by the partner's self-reported HIV status (indexed in a column) was created (table 1).

Perceptions by self-report were then coded as a risky misperception when: (1) a respondent's perception of the partner's status was his being negative while his partner's self-report was positive $\left(\mathrm{n}_{12}=19\right)$ and $(2)$ a respondent's perception of the partner's status as negative while the partner's self-report was status unknown $\left(\mathrm{n}_{13}=17\right)$.

Risky sex. Risky sex was measured by the involvement of drug use before or during sex (yes or no) and/or having unprotected sex the last time the dyad had sex (yes or no).

Relationship dynamics. Respondents were asked to answer 14 questions about their relationships with their sex partners. Questions were related: (1) the connection felt with the partner ('connect'), (2) confidence in the partner ('confide'), (3) emotional attachment to the partner ('emotion'), (4) partner's concern for the respondent ('matter'), (5) respondent's concern for the partner ('care'), (6) respondent's willingness to live with the partner ('live'), (7) knowledge of the partner's whereabouts ('contact'), (8) respondent's willingness to spend time with the partner ('hang out'), (9) respondent's willingness to be seen with the partner ('seen'), (10) respondent's willingness to lend money to the partner ('ego-money'), (11) the partner's willingness to lend money to the respondent ('partner-money'), (12) trust in the partner ('ego-trust'), (13) partner's trust in the respondent ('partner-trust') and (14) partner's honesty with the respondent ('partner-honest') (see the online supplement for questionnaire items). All items were scaled from 1 (not at all) to 10 (very much/extremely) or 1 (very little) to 10 (very much).

\section{Data}

In the original study, 334 men (84\%) and 62 women (16\%) were interviewed. The 396 respondents were also asked about their contacts' characteristics, HIV status, risky sexual behaviours and relationships to the respondent. Information was obtained on 4880 respondent-contact dyads. Contacts provided data on an average of 12 others $(S D=10, \operatorname{Min}=1, \operatorname{Max}=59)$. Of the 4880 dyads, only 179 dyads in which both the participant and the contact were interviewed were included in the analysis. Data on 11 of these were excluded due to missing relational information. Thus, the analytical sample used for this study consisted of 168 respondent-contact dyads (including two man-woman dyads) that involved sex. These 168 dyads comprised 116 unique male respondents. Among these 116 respondents, 33 (28.5\%) were focal participants, 53 (45.7\%) were secondary contacts and 30 (25.9\%) were tertiary contacts.

\section{Exploratory factor analysis}

Exploratory factor analysis, using the iterated principal-factor estimation method, ${ }^{22}$ was conducted to identify relationship dynamics. With the assumption that the factors were correlated, loadings were rotated (oblique rotation). Then, parallel analysis was conducted to determine the number of factors to be retained. ${ }^{23}$ In the parallel analysis, the eigenvalues obtained from the 10 correlation matrices that were generated from random datasets were averaged. The averaged eigenvalues were compared with the eigenvalues derived from the factor model. When the former was larger than the latter, factors were indicated as mostly random noise. ${ }^{23}$ Then, the scale reliability coefficient (Cronbach's $\alpha$ ) of each extracted factor was computed for derived factors with more than two items with loadings $>0.40$. The final factors were calculated by computing regression coefficients based on all items included in the regression, which were included as relationship dynamics variables in the subsequent regression analysis.

\section{Regression analysis}

The unit of analysis for the study was the sexual dyad. Because $32.8 \%$ of the 116 respondents named more than one sex

Table 1 Cross-tabulation of respondent's knowledge by sex partner's self-report on his HIV status (dyads $=168$ )

\begin{tabular}{lllll}
\hline & \multicolumn{2}{l}{ Sex partner's self-report on HIV status } & & Unknown \\
\cline { 2 - 5 } Respondent's knowledge & Negative & Positive & $\mathrm{n}_{13}=17(15.9)$ & Total \\
\hline Negative (\%) & $\mathrm{n}_{11}=71(66.4)$ & $\mathrm{n}_{12}=19(17.8)$ & $\mathrm{n}_{23}=6(9.8)$ & $\mathrm{n}_{1+}=107(100)$ \\
Positive (\%) & $\mathrm{n}_{21}=15(24.6)$ & $\mathrm{n}_{22}=40(65.6)$ & $\mathrm{n}_{3+}=23$ & $\mathrm{n}_{2+}=61(100)$ \\
Total & $\mathrm{n}_{1+}=86$ & $\mathrm{n}_{2+}=59$ & $\mathrm{n}_{++}=168$ \\
\hline
\end{tabular}

Parentheses indicate row percentage. 'Risky misperception' by a respondent of his partner's HIV status was operationalised by combining the following three cells: (1) respondent's knowledge being negative while his partner's being positive $\left(n_{22}=19\right)$ and $(2)$ respondent's knowledge being negative while his partner's being unknown ( $\left.n_{13}=17\right)$, totalling $36(21.4 \%)$ cases of risky discrepancy out of 168 dyads. 
partner, dyadic data were treated as correlated binary data clustered on the respondent. To account for clustering, a generalised estimating equation ${ }^{24}$ with a logit link function was used to estimate the population-averaged odds of misperceiving the partner's HIV status as a function of the covariates in the model. An exchangeable correlation structure with robust empirical variance estimates was specified to address potential misspecification of the correlation structure. All analyses were conducted using Stata V.13.

\section{RESULTS}

\section{DESCRIPTIVE STATISTICS}

Table 2 shows descriptive statistics for HIV status, sociodemographic characteristics and risky sexual behaviour of both respondents and their sex partners as well as their dyadic characteristics and relationship dynamics (dyads=168, with 116 MSM).

The majority of the sample (86\%) had traded sex for money and had an average of 36 partners in the 30 days before the interview. Approximately two-thirds of sex partners (66\%) were reported by respondents to trade sex for money. Of the sample, $32 \%$ reported being HIV positive and 55\%, negative. The remainder was of unknown status.

\section{Exploratory factor analysis}

The result of the exploratory factor analysis indicated that the first six of the eigenvalues were greater than the eigenvalues averaged over 10 replications. Therefore, the first six factors, ranging from 0.21 to 8.83 , were retained. The original items were grouped into six latent factors.

The first factor comprised the highly loaded items of 'connect' (0.79), 'confide' (0.51) and 'emotion' (0.62) (Cronbach's $\alpha=0.91$ ) to describe intimate relationships. The second factor comprised the highly loaded items of 'matter' (0.97), 'care' (0.73) and 'live' (0.49) (Cronbach's $\alpha=0.88$ ) to describe committed relationships. The third factor comprised 'contact' (0.87), 'hang out' (0.88) and 'seen (0.78) (Cronbach's $\alpha=0.92)$ to describe socialising. The fourth factor comprised 'ego-money' (0.42) and 'partner-money' (0.88) to describe a financial dimension. A fifth factor comprised 'ego-trust' (0.58) and 'partner-trust' (0.72) to describe the trust dimension. A sixth factor comprised the item of 'partner-honest' and was treated as a single item dimension, honesty (0.81). Eigenvalues $(>0.2)$, uniqueness statistics and loadings $(>0.4)$ for each factor are provided in the table in the online supplement.

\section{Regression analysis}

Table 3 shows the adjusted ORs (AOR) for the relationship dimensions.

The dimension commitment was found to be associated with a decrease in the odds of misperceiving the partner's HIV status $(\mathrm{AOR}=0.45 ; \mathrm{p}=0.039)$. Higher trust was found to increase the odds of misperceiving the partner's HIV status (AOR $=2.78$; $\mathrm{p}=0.026$ ). Other relational dimensions, intimacy (connect, confide and emotion), socialising (contact, hang out and seen), financial (ego-money and partner-money) and honesty (partnerhonest), were not significantly associated with misperception of the partner's status.

Risky behaviour. Having neither a drug use relationship nor unprotected sex was associated with risky misperception of the partner's HIV status.

Respondent's and partner's characteristics. HIV-negative respondents had greater odds of misperceiving the sex partner's HIV status than did HIV-positive respondents (AOR=7.69 (1/
Table 2 Percentages or means (SDs; min and max) for respondent and his relational characteristics (MSM=116, dyads=168)

Frequencies (percentages) or mean (SD; min, max)

$\begin{array}{ll}\text { Respondent's (ego's) characteristics/behaviour ( } N=116) \\ \text { HIV status } \\ \text { Negative } & 55 \% \\ \text { Positive } & 32 \% \\ \text { Unknown } & 13 \% \\ \text { Age } & 34.8(8.4 ; 18,62) \\ \text { Race/ethnicity } & \\ \text { Black } & 44 \% \\ \text { White } & 48 \% \\ \text { Hispanic } & 8 \% \\ \text { Homeless } & 50 \% \\ \text { Years of schooling } & 11.6(2.4 ; 6,19) \\ \quad \text { Number of lifetime arrest } & 11.9(12.6 ; 0,50) \\ \text { Risky sexual behaviour } & \\ \text { Experience in transactional sex } & 86 \% \\ \text { Number of sex partners } & 36.6(41.5 ; 1,150)\end{array}$

Respondent's (ego's) belief/perception about his sex partners' characteristics/ behaviour

Age $33.3(8.1 ; 18,65)$

Experience in transactional sex

$66 \%$

Dyadic variables (dyads=168)

Dyadic characteristics

Black-Black couples $\quad 43 \%$

White-White couples $\quad 32 \%$

Couples with mixed race/ethnicity $\quad 26 \%$

Gay-gay couples $\quad 33 \%$

Risky sexual relationships

Drug use before or during sex $\quad 82 \%$

Unprotected sex $\quad 66 \%$

Interpersonal relationships

Connect

Confide

Emotion

Matter

Care

Live

Contact

Hang out

Seen

Ego-money

Partner-money

Ego-trust

Partner-trust

$5.8(3.3 ; 1,10)$

$5.6(3.4 ; 1,10)$

$5.0(3.4 ; 1,10)$

$4.9(3.5 ; 1,10)$

$5.5(3.7 ; 1,10)$

$5.1(3.8 ; 1,10)$

$6.9(3.0 ; 1,10)$

$6.3(3.0 ; 1,10)$

$6.8(3.0 ; 1,10)$

$5.4(3.8 ; 1,10)$

$6.1(3.6 ; 1,10)$

$6.3(3.3 ; 1,10)$

$6.3(3.2 ; 1,10)$

Partner-honest

Number of sex partners was truncated at a maximum of 150 .

MSM, Men who have sex with men.

0.13) $\mathrm{p}=0.002)$. Almost as risky is that non-sex workers had greater odds of misperceiving the partner's status than did male sex workers $(\mathrm{AOR}=3.45(1 / 0.29) ; \mathrm{p}=0.039)$. However, a respondent's knowledge of the sex partner as a sex worker was not associated with misperception. Additionally, older sex partners were associated with decreased odds of misperception of HIV status, but the upper 95\% CI was very close to 1 $(\mathrm{AOR}=0.90 ; \mathrm{p}=0.042)$.

Dyadic characteristics. Dyads in which both partners were African American were associated with increased odds of misperceiving the partners' HIV status; however, the effect was 
Table 3 GEE results of adjusted ORs (AOR), standard errors, $95 \% \mathrm{Cls}$, and $\mathrm{p}$ values in parenthesis (dyads $=168, \mathrm{~N}=116$ )

\begin{tabular}{|c|c|c|}
\hline Respondent characteristics & $\begin{array}{l}\text { Risky misperception } \\
\text { of partner's HIV status } \\
\text { AOR (SE; } 95 \% \mathrm{Cl} \text { ) }\end{array}$ & $p$ Values \\
\hline \multicolumn{3}{|l|}{ Respondent's characteristics/behaviour } \\
\hline HIV positive & $0.13(0.08 ; 0.04$ to 0.47$)$ & 0.002 \\
\hline HIV unknown & $0.46(0.39 ; 0.09$ to 2.41$)$ & \\
\hline Age & $1.03(0.03 ; 0.97$ to 1.10$)$ & \\
\hline Homeless & $1.11(0.48 ; 0.47$ to 2.60$)$ & \\
\hline Years of schooling & $0.96(0.09 ; 0.80$ to 1.16$)$ & \\
\hline Number of lifetime arrest & $0.98(0.16 ; 0.71$ to 1.34$)$ & \\
\hline Number of sex partners & $1.06(0.09 ; 0.91$ to 1.25$)$ & \\
\hline Experience in transactional sex & $0.29(0.17 ; 0.09$ to 0.94$)$ & 0.039 \\
\hline \multicolumn{3}{|l|}{ Respondent's knowledge about partners } \\
\hline Partner's age & $0.90(0.05 ; 0.81$ to 1.00$)$ & 0.042 \\
\hline $\begin{array}{l}\text { Partner's experience in transactional } \\
\text { sex }\end{array}$ & $1.19(0.67 ; 0.39$ to 3.60$)$ & \\
\hline \multicolumn{3}{|l|}{ Dyadic characteristics } \\
\hline $\begin{array}{l}\text { African American-African American } \\
\text { couples }\end{array}$ & $5.11(4.39 ; 0.95$ to 27.51$)$ & 0.057 \\
\hline Caucasian-Caucasian couples & $0.16(0.11 ; 0.04$ to 0.65$)$ & 0.011 \\
\hline Gay-Gay couples & $3.57(2.29 ; 1.01$ to 12.56$)$ & 0.048 \\
\hline \multicolumn{3}{|l|}{ Risky sexual relationships } \\
\hline Drug use before or during sex & $0.84(0.51 ; 0.24$ to 2.97$)$ & \\
\hline Unprotected sex & $1.28(0.75 ; 0.40$ to 4.05$)$ & \\
\hline \multicolumn{3}{|l|}{ Interpersonal relationships } \\
\hline $\begin{array}{l}\text { Intimacy (connected, confide, } \\
\text { emotion) }\end{array}$ & $1.89(1.00 ; 0.66$ to 5.35$)$ & \\
\hline Commitment (matter, care, live) & $0.45(0.17 ; 0.21$ to 0.96$)$ & 0.039 \\
\hline Socialising (contact, hang out, seen) & $0.82(0.31 ; 0.39$ to 1.73$)$ & \\
\hline $\begin{array}{l}\text { Financial (ego-money, } \\
\text { partner-money) }\end{array}$ & $0.66(0.27 ; 0.30$ to 1.47$)$ & \\
\hline Trust (ego-trust, partner-trust) & $2.78(1.28 ; 1.13$ to 6.87$)$ & 0.026 \\
\hline Honesty (partner-honest) & $0.71(0.29 ; 0.32$ to 1.60$)$ & \\
\hline
\end{tabular}

marginal $(\mathrm{AOR}=5.11 ; \mathrm{p}=0.057)$. Conversely, dyads in which both partners were Caucasian were associated with decreased odds of misperception ( $\mathrm{AOR}=0.16 ; \mathrm{p}=0.011$ ). Dyads in which both partners self-identified as gay were found to be associated with increased odds of misperception ( $\mathrm{AOR}=3.57 ; \mathrm{p}=0.048)$.

\section{DISCUSSION}

Our findings indicated that six dynamic components of sexual relationships appear to associate with knowledge of HIV status among male sex workers: intimacy, commitment, socialising, financial, trust and honesty. Among these, greater trust was associated with higher odds of misperceiving a sex partner's HIV status. This result is consistent with previous studies that have found that greater trust in a sexual relationship is related to engaging in risky sexual behaviours. ${ }^{10}{ }^{11}$ Studies have shown that homeless men have greater feelings of trust in sex partners of short duration than do non-homeless men. ${ }^{12}$ More than half the sample in this study were homeless at the time that they were interviewed. This may account for the strong association between greater trust and misperception of a partner's HIV status.

Conversely, the findings showed that stronger feelings of commitment to a sex partner (i.e., respecting what a partner thinks, caring about a partner and willingness to live with a partner) were associated with correctly perceiving a partner's HIV status. This result is consistent with other studies that report that individuals in committed partnerships are more likely to accurately perceive their sex partner's infection status. ${ }^{25}$ These findings suggest that stronger relationships are an important component in communications about HIV status in sexual encounters, which can be distinguished from intimacy and honesty. We found that financial and socialising relationships (frequency of contact, hanging out and seeing) were not associated with misperceiving the partner's HIV status. Given that these men also used drugs extensively, it is interesting that drug use was not associated with misperception of HIV status.

Interestingly, male sex workers' perceptions of their sex partners' HIV status were likely to be more accurate than were others in the study. This finding may be because sex workers tend to assume that all sex partners are positive, given the risk environment in which they work. ${ }^{3}$ Assuming that all partners are HIV positive may decrease the likelihood of an incorrect assumption about a partners' status. The study also found that HIV-negative individuals and couples in which both partners were gay were more likely to misperceive their partners' status. HIV-negative MSM who engaged in unprotected anal sex with their primary partners tend to assume that the partner was negative. ${ }^{26}$ This may be strongly related to feelings of trust in the partner. Conversely, dyads in which both partners were Caucasian or in which one's partner was older, were more likely to have correct knowledge of their partner's status.

Our study has certain limitations. First, the study defined sex partners as 'ever having had sex'. Some forms of sex carry a lesser risk of HIV transmission. Second, the majority of the sample was MSM who had exchanged sex for money, which represents only a part of the risk-potential partnerships of HIV transmission. Therefore, our results are not generalisable to other MSM populations. Future research should test the conclusions against a different dataset to claim any generality for our findings.

Despite these limitations, our study provides a more comprehensive understanding of the relational dynamics that may enhance or curtail HIV risk in sexual relationships. Social networks have substantial effects of HIV risk perceptions among MSM, and the process through which they are formed has been underscored. ${ }^{9}$ The study addressed this issue in the context of sexual encounters that involve a sample of most at-risk MSM, i.e., men who use drugs and exchange sex for money. HIV prevention efforts that focus on sexual partnerships, such as couple-based voluntary HIV counselling and testing, ${ }^{27}$ could be more effectively delivered with a nuanced consideration of their relational constituents.

\section{Key messages}

- Sexual partnerships that involve the most at-risk MSM consist of six relational dimensions: intimacy, commitment, socialising, financial, trust and honesty.

- Strong trust with sex partners was a risk factor for incorrectly knowing the sex partner's HIV status.

- Strong feelings of commitment to the partner (i.e., respecting partner's thoughts, caring and willingness to live together) were associated with non-risk knowledge of the partner's HIV status.

- HIV prevention efforts in couple-based voluntary HIV counselling should identify and adjust for the potential impacts of the six relational dimensions of the interpersonal relationship. 


\section{Handling editor Stefan Baral}

Acknowledgements We also acknowledge Ju Yeong Kim for assisting the validation of the data and results.

Contributors KF initiated this study, formulated the conception and conducted data analysis. MLW and MWR assisted in formulating the conception, acquired data and interpreted the results. All authors were involved in drafting the article or in revising the intellectual content. All authors approved the submitted version.

Funding This study used the dataset collected by social network project funded by the following National Institutes of Health grant: National Institutes of Health/NIDA R01DA015025. This study was, in part, supported by the National Institutes of Health/NIMH 1R01MH100021.

\section{Competing interests None.}

Ethics approval University of Texas Health Science Center at Houston.

Provenance and peer review Not commissioned; externally peer reviewed.

Open Access This is an Open Access article distributed in accordance with the Creative Commons Attribution Non Commercial (CC BY-NC 4.0) license, which permits others to distribute, remix, adapt, build upon this work non-commercially, and license their derivative works on different terms, provided the original work is properly cited and the use is non-commercial. See: http://creativecommons.org/ licenses/by-nc/4.0/

\section{REFERENCES}

1 Centers for Disease Control and Prevention CDC. HIV among gay, bisexual, and other men who have sex with men. National Center for HIV/AIDS, Viral Hepatitis, STD, and TB Prevension, Division of HIV/AIDS Prevention. 2013.

2 Reisner SL, Mimiaga MJ, Mayer KH, et al. Tricks of the trade: sexual health behaviors, the context of HIV risk, and potential prevention intervention strategies for male sex workers. J LGBT Health Res 2008:4:195-209.

3 Mimiaga MJ, Reisner SL, Tinsley JP, et al. Street workers and internet escorts: Contextual and psychosocial factors surrounding HIV risk behavior among men who engage in sex work with other men. J Urban Health 2008;86:54-66.

4 Williams ML, Timpson S, Klovdahl A, et al. HIV risk among a sample of male sex workers. AIDS 2003;17:1402-4.

5 Williams ML, Bowen AM, Timpson S, et al. Drug injection and sexual mixing patterns of drug-using male sex workers. Sex Transm Dis 2003:30:571-4.

6 Friedman SR, Aral S. Social networks, risk-potential networks, health, and disease. J Urban Health 2001;78:411-18.

7 Schneider JA, Cornwell B, Ostrow D, et al. Network mixing and network influences most linked to HIV infection and risk behavior in the HIV epidemic among Black Men Who Have Sex With Men. Am J Public Health 2013;103:e28-36.

8 Eaton LA, Kalichman SC, O'Connell DA, et al. A strategy for selecting sexual partners believed to pose little/no risks for HIV: serosorting and its implications for HIV transmission. AIDS Care 2009;21:1279-88.
9 Kohler H-P, Behrman JR, Watkins SC. Social networks and HIVIAIDS risk perceptions. Demography 2007;44:1-33.

10 Masaro CL, Dahinten VS, Johnson J, et al. Perceptions of sexual partner safety. Sex Transm Dis 2008:35:566-71.

11 Motoya ID, Bell DC. Perceiver and relationship effects on perceptions of HIV status: a naturalistic study in a high drug use sample. Health Psychol 2006;25:771-7.

12 Brown RA, Kennedy DP, Tucker JS, et al. Sex and relationships on the street: how homeless men judge partner risk on skid row. AIDS Behav 2012;16:774-74.

13 Jason MW, Keith $\mathrm{H}$. Factors associated with regular HIV testing among a sample of US MSM with HIV-negative main partners. JAIDS 2013;64:417-23.

14 Latkin CA, Yang C, Tobin K, et al. Social network predictors of disclosure of MSM behavior and HIV-positive serostatus among African American MSM in Baltimore, Maryland. AIDS Behav 2012;25:535-42.

15 Flowers P, Davis MDM. Understanding the biopsychosocial aspects of HIV disclosure among HIV-positive gay men in Scotland. J Health Psychol 2012;18:711-24.

16 Nagaraj S, Segura ER, Peinado J, et al. A cross-sectional study of knowledge of sex partner serostatus among high-risk Peruvian men who have sex with men and transgender women: implications for HIV prevention. BMC Public Health 2013;13:181.

17 Sanford T, Yi H, Know J, et al. Sexual partnership types as determinant of HIV risk in South African MSM: an event-level cluster analysis. AIDS Behav 2013;17:S23-32.

18 Heckathorn DD. Respondent driven sampling II: Deriving valid population estimates from chainreferral samples of hidden populations. Soc Prob/ 2002;49:11-34.

19 Watters J, Biernacki P. Targeted sampling: Options for the study of hidden populations. Soc Probl 1989;36:416-30.

20 Williams ML, Atkinson J, Klovdahl AS, et al. Spatial bridging in a network of drug-using male sex workers. J Urban Health 2005;82(Suppl 1):i35-42.

21 Williams ML, Ross M, Atkinson JA, et al. An investigation of concurrent sex partnering in two samples having large numbers of sex partners. Int I STD AIDS 2006;17:309-14.

22 StataCorp. Stata: Release 13. Statistical Software. College Station, TX: StataCorp LP, 2013.

23 Ender, P.B. 2010. fapara: Stata Command to Perform Parallel Analysis for Factor Analysis. UCLA: Statistical Consulting Group. https://urldefense.proofpoint.com/v1/ url?u=http://www.ats.ucla.edu/stat/stata/ado/analysis/\&k=yYSsEqip9\%2FcljLHUh VwlqA\%3D\%3D\%0A\&r=7e7d8Xgm\%2Ba3m7eDFB86u4WrzD1v2QDv6tiv2H1j Gc0w\%3D\%0A\&m=Tup6YL2pLAmN94w7\%2BkxNRcbDSn7jyplivA8qLmrgDT4\% 3D\%0A\&s=8f6ba7ee77c842b8358c610c83100dee62e1092768c8eaec0fb50 dd645251575

24 Liang K, Zeger SL. Longitudinal data analysis using generalized linear models. Biometrika 1986;73:13-22.

25 Niccolai LM, Farley TA, Ayoub MA, et al. HIV-infected persons' knowledge of their sexual partners' HIV status. AIDS Educ Prev 2002;14:183-9.

26 Crepaz N, Marks G, Mansergh G, et al. Age-related risk for HIV infection in men who have sex with men: Examination of behavioral, relaitonship, an serostatus variables. AIDS Educ Prev 2000;12:405-15.

27 Stephenson R, Sullivan PS, Salazar LF, et al. Attitudes towards couples-based HIV testing among MSM in three US cities. AIDS Behav 2011;15:S80-S7. 